\title{
Influence on nivalenol by food processing
}

\author{
Hisashi KAMIMURA* \\ 上村＼cjkstart尚*：食品加工におけるニバレノールの動態
}

\begin{abstract}
Introduction
Fusarium sp. affects various agricultural products and causes Bakanae disease of Rice plants, Stem wilt of Broad-bean, Fusarium blight and so forth. Also Fusarium sp. harms kernels of wheat, barley, corn etc. and inhibits full growth of those kernels. Of these, Fusarium sp. has been treated mainly as a plant pathogen in the past. However, recently, it has been proved that Fusarium sp. produces trichothecen mycotoxins such as nivalenol, deoxynivalenol and T-2 toxin as well as other kinds of mycotoxin such as zearalenone and fumonisins. As the actual condition of contamination by fusarium mycotoxins over staple cereals became clear, the problem of fusarium mycotoxins became one of the most important dietary hgygiene issues.

Not noly do we need to have a deep understanding of the actual condition of fusarium mycotoxin contamination in agricultural products as well as in food product made from them, but we should also do some research on whether or not, when food materials such as cereals are contaminated by mycotoxin, it remains after the cooking process, accumulates in human bodies and has any influence on them ${ }^{1-4)}$.

In our study we cooked those foods which had proved by research on the actual condition of fusarium mycotoxin contamination, to be contaminated in the natural environment. We give a report here of whether or not mycotoxin remains after cooking and of how mycotoxin is influenced by food product manufacturing processes.
\end{abstract}

\section{Influence of cooking process on fusarium mycotoxin}

\section{Stability of the fusarium mycotoxin against heat}

By heating the fusarium mycotoxin within the range of $100-210^{\circ} \mathrm{C}$, temperatures which are seen during a normal cooking process, we investigated the stability of fusarium mycotoxin against heat. The result of this research appears in Fig. 1. When boiled $\left(100-120^{\circ} \mathrm{C}\right)$, mycotoxin remained almost $100 \%$ after 45 -minute heating. As the temperature rose,-such as when frying (about $150^{\circ} \mathrm{C}$ ) and when deep frying (about $180^{\circ} \mathrm{C}$ ), the mycotoxin started decomposition. In the case of grilling (about $210^{\circ} \mathrm{C}$ ), the nivalenol type of toxin rapidly decreased to $10 \%$ after a 15-minute heating. In conclusion, we hypothesize that mycotoxin decompose as the temperature rise; but that part of the mycotoxin remains through ordinary cooking methods in terms of

* Tokyo Metropolitan Research Laboratory of Public Health (24-1, Hyakunincho 3-chome, Shinjuku, Tokyo 169)

東京都立衛生研究所（テ169 東京都新宿区百人町 3-24-1) 
heating temperature as well as heating time.

\section{Dissolution of fusarium mycotoxin into water}

Fusarium sp. produces various kinds of mycotoxins, from the ones with high polarity to the ones with low polarity. Nivalenol, which has especially high polarity, can be removed by washing with water during food processing.

First, we steeped in water wheat that had been proved to be contaminated in the natural environment. The results are shown in Table 1. After steeping the wheat in water for 1 hour, filtrated it and separated the wheat from the water. About $30 \%$ of the mycotoxin was detected in the remaining water.

\section{Stability of fusarium mycotoxin against food additives}

Using food additives such as manufacturing materials (alkali and acids) and a bleacher (sodium sulfite), we investigated their influence on the fusarium mycotoxin. In the case of a alkaline solution, the fusarium mycotoxin was proved to be unstable and to become more unstable as the strength of the solution increases. Furthermore, the fusarium mycotoxin was also provide to be unstable in a solution of sodium sulfite. In the case of the wheat which had been contaminated in the natural environment, we did not get any detection of nivalenol after steeping the wheat for 10 hours in a $0.4 \%$ sodium sulfite solution. These results are shown in Fig. 2.

\section{Influence on fusarium mycotoxin by a cooking process}

As previous research on mycotoxin contamination in foods on the market shows, fusarum mycotoxins, such as nivalenol, deoxynivalenol, and zearalenone, are frequently detected in wheat, barley and corn as well as in food products made from them. We cooked those foods

Table 1 Residual rate of deoxynivalenol and nivalenol in naturally infected barley by water soaking.

\begin{tabular}{lccccc}
\hline \hline \multirow{2}{*}{ Sample } & \multicolumn{2}{c}{ Deoxynivalenol } & & \multicolumn{2}{c}{ Nivalenol } \\
\cline { 2 - 2 } \cline { 5 - 6 } & $\begin{array}{c}\text { Found } \\
(\mathrm{ppm})\end{array}$ & $\begin{array}{l}\text { Residual } \\
\text { rate (\%) }\end{array}$ & & $\begin{array}{c}\text { Found } \\
(\mathrm{ppm})\end{array}$ & $\begin{array}{c}\text { Residual } \\
\text { rate (\%) }\end{array}$ \\
\hline Before steeping & 4.7 & & & 4.5 & \\
After steeping & 3.3 & 71 & & 2.5 & 63 \\
Soak & 1.5 & 32 & & 1.3 & 29 \\
\hline
\end{tabular}

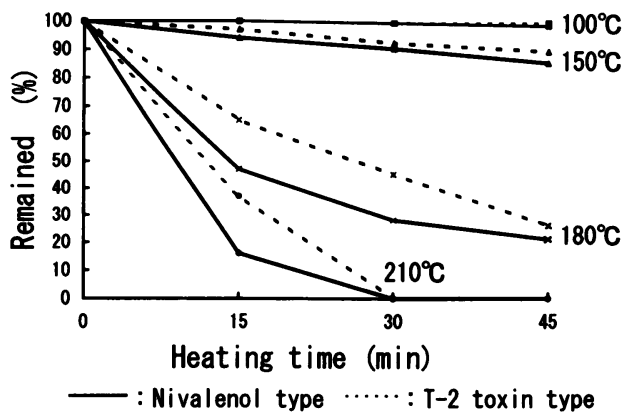

Fig. 1 Stability of trichothecenes against heat treatment. 


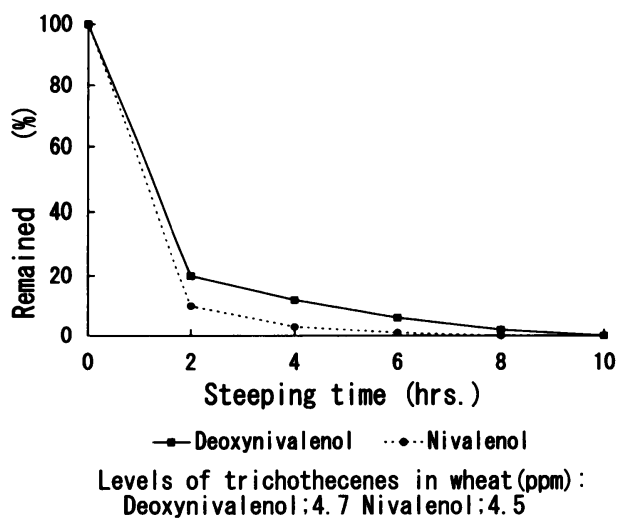

Fig. 2 Stability of trichothecenes in naturally infected wheat steepting with $0.4 \% \mathrm{Na}_{2} \mathrm{SO}_{3}$.

Table 2 Behavior of fusarium mycotoxins by the cooking process.

\begin{tabular}{clcc}
\hline \hline Sample & Mycotoxin & $\begin{array}{c}\text { Before cooking } \\
(\mathrm{ppb})\end{array}$ & $\begin{array}{c}\text { After cooking } \\
(\mathrm{ppb})\end{array}$ \\
\hline Pressed barley & Nivalenol & 282 & 224 \\
& Deoxynivalenol & 264 & 245 \\
Coix seed & Zearalenone & 53 & 49 \\
Spaghetti & Zearalenone & 840 & 770 \\
& Deoxynivalenol & 14 & 8 \\
\hline
\end{tabular}

which had been proved to be contaminated. Table 2 shows the results. First, we added water to the pressed barley in which nivalenol, deoxynivalenol, and zearalenone had been detected. After boiling the pressed barley for 15 minutes, we observed 195-247 ppb of nivalenol, which was $282 \mathrm{ppb}$ before cooking. One the average, $224 \mathrm{ppb}$ of nivalenol was detected, which was slightly lower before cooking. We had the same result with deoxynivalenol as well as zearalenone. With these, we hypothesize that nivalenol, deoxynivalenol, and zearalenone hardly decompose in water when boiled. We had similar results when boiled coix seed (seed of coix lacryma-jobi var. ma-yuen) and spaghetti, and reached the hypothesis that, when boiled, the fusarium mycotoxin does not decompose in water and remains almost completely in food.

\section{Influence of manufacturing process on fusarium mycotoxin}

\section{Cornstarch}

Cornstarch is manufactured as follows. After steeping corn for 50-60 hours in a $0.2-0.3 \%$ sulfurous acid solution, it is roughly ground and the germs are separated from the rest. After the germs have been further ground of pieces, starch milk is obtained and is processed by a centrifugal separator. Then, by washing with water, refining, dehydrating and drying, they make the cornstarch product.

Even when food materials are contaminated by mycotoxin, if food processing includes steeping them in a sulfurous acid solution as well as water-washing, high polarity nivalenol and 
fumonisin can be completely removed. For more than 20 years, we have been investigating mycotoxin contamination in foods on the market, but so far we have never detected mycotoxin in cornstarch.

\section{Beer}

Fusarium mycotoxin is often detected in beer barley (Nijo Barley), the primary material of beer as well as in corn grits, the second primary material of beer. However, in finished beer products, mycotoxin is not detected at all. This is mainly because of the steeping and fermentation processes used in manufacturing beer. In the steeping process, barley is steeped for 6 hours and then is dried for another 6 hours. The same procedure is repeated four times. At this stage, mycotoxins with high polarity such as nivalenol can be removed. Even when a small amount of mycotoxin remains, it decomposes in the fermentation process and does not remain in finished produets.

\section{Conclusion}

From these research results, we conclude that many types of mycotoxin do not decompose by ordinary cooking methods conducted at home, and that they remain in food and accumulate in human bodies. In the case of some food products, even when mycotoxin is detected in primary materials, it can be removed in manufacturing process and does not remain in finished product.

Prevention of mycotoxin contamination depends on handling of agricultural products at various stages from harvesting to storing. People in agriculture must be made more aware of how important it is to prevent mycotoxin contamination, and the same heightened awareness is also essential for those in food manufacturing.

\section{References}

1) Kamimura, H., Nishijima, M., Saito. K., Ibe, A., Naoi, Y.: Proc, Jap. Assoc. Mycootoxicol., 8,14 (1978).

2) Kamimura, H., Nishijima, M., Saito, K., Yasuda, K., Ibe, A., Nagayama, T., Ushiyama, H., Naoi, Y.: J. Food Hyg. Soc. Japan, 20, 352 (1979).

3) Kamimura, H.: Proc. Jap. Assoc. Mycotoxicol., 26, 13 (1987).

4) Kamimura, H., Tabata, S., Tamura, I., Yasuda, K., Ushiyama, H., Hashimoto, H., Nishijima, M., Nishima, T. : J. Food Hyg. Soc. Japan, 28, 322 (1987).

5) Kamimura, H.: Mycotoxins, 43, 27 (1996). 